\title{
Nurse's Awareness of the Relationship Between Suicidal Ideation and Schizophrenic Patient's Positive/Negative Symptoms.
}

\author{
ZainabEedKmalKlila1, Somaya El-SayedAbou-Abdou. \\ Psychiatric and Mental HealthNursing1, 2, Faculty of Nursing, Suez Canal University
}

\begin{abstract}
Background: Suicidal thoughts and behaviors are very common among schizophrenic patients. Nurses have vital role in decreasing incidence of suicide among schizophrenic patients through increase their awareness of the relationship between suicidal ideation and positive / negative symptoms of schizophrenia. Aim of the study: study aims to assess nurse's awareness of the relationship between suicidal ideation and schizophrenic patients' positive/negative symptoms. Research methods: A descriptive exploratory research design was utilized. A convenience sample was selected in this study. The subject of the present study consisted of (70) nurses (males and females) who are working in Port-Said Psychiatric Mental Health Hospital (PSPMHH).Tools: A self-reports study tools were developed by the researcher and it consists of 3 tools. First tool: Socio-demographic data. Second Tool: Nurse's knowledge about schizophrenic disorder. It consisted of three parts. Third Tool: Nurse's awareness of suicidal ideation in schizophrenic patients. It consisted of three parts. Results: There is no statistically significance relationship between socio-demographic characteristic and nurse's awareness of positive \&negative symptoms of schizophrenia. While, there is statistically significance relationship between scholastic psychiatric experience \& total nurse's awareness of the relationship between suicidal ideation and positive / negative symptoms of schizophrenia. Conclusion: Majority of the studied nurses subject weren't aware of positive / negative symptoms of schizophrenic patients. Nearly three quadrant of studied nurses subject weren't aware of the relationship between suicidal ideation and positive/negative symptoms of schizophrenic patients. Majority of the studied nurses subject don't have the ability to recognize different clues that may indicate early intention for suicide made by schizophrenic patients. Recommendation: Orientation programs/seminars should be developed about the existence of the relationship between specific positive \& negative symptoms of schizophrenia and suicidal ideation among Egyptian patients.
\end{abstract}

Key words: Nurses awareness, Schizophrenia, Positive/ Negative symptoms", "Suicidal ideation Corresponding Author: Zainab Eed KmalKlila, Cell phone No. 01013234383 (email:Zainab.klila@yahoo.com)

\section{Introduction}

Self-awareness is a psychological state in which people are aware of their traits, feelings and behavior. Alternately, it can be defined as the realization of oneself as an individual entity (Crisp\&Turner,2014).In our study awareness means perception and knowledge of nurses toward relationship between suicidal ideation and schizophrenic patient's positive and negative symptoms .

Suicide is one of the leading causes of premature death among schizophrenia patients. It has been reported that $18-55 \%$ of schizophrenia patients attempt suicide during 
the disorder, and $2-13 \%$ of the patients die from suicide (Isik,2007). In retrospective studies which investigated medical records of 72 schizophrenic patients in a multi-central study in Turkey found that $52 \%$ of the patients had suicidal thoughts or suicidal attempts and $28 \%$ of those patients tried to commit suicide at least once, while in some follow-up studies, 10-13\% of schizophrenic patients succeed in committing suicide (Yildiz, Yazici\&Boke,2010).

The importance of suicide cannot be ignored as the United States alone sees more than 30000 suicide victims annually .Among those particularly at risk for committing suicide are individuals suffering from schizophrenia and other chronic psychotic disorders. Suicidal behavior is a major public health problem and schizophrenia is markedly affected by suicide. Early and continuous monitoring of suicidality is important and high- risk groups are easily identified (Koslow,Ruiz\&Nemeroff,2014).

Command auditory hallucinations are the psychotic symptoms most frequently associated with suicidal behavior (Taylor\&Hor,2010), perhaps particularly so in the most vulnerable-to suicide of these patients. Command hallucinations command a person to do things. One of the things a voice might command a person with schizophrenia to commit suicide. Because the person with schizophrenia may not be able to recognize that the voice is not real, the command to commit suicide can be very compelling (Yung\&McGorry,2012).

Suicidal behaviors are accompanied by suicidal ideation, so the identification of risk factors is a great important . Known risk factors for suicide in schizophrenia include male, gender, a negative attitude toward treatment, impulsive behavior, alcoholism, social isolation, poor psychosocial functioning, depression, previous suicide attempts or behavior, chronicity of illness with many acute episodes and remission, awareness of the deteriorative effects of the disorder, fear of further deterioration and a loss of confidence in treatment(Kelly,Shim,Feldman,Yu\&Conley $.2004)$.

Clinical description of the patients who commit suicide and the identification of risk factors are fundamental for the design of care strategies. Most suicide acts occur during a period of high vulnerability: the first year of disease. So, the prevention of suicide must be a major priority for the nurses, but also for the family and social workers: research and correction of risk factors, evaluation and treatment of suicidal behavior. Cares can use pharmacological means, psychotherapy, psychosocial and psycho-educative programs to fight against loss of social insertion and stigmatization(Gavaudan,Besnier\&Lançon, 2006).

Suicide is considered more preventable than any other cause of death, it means saving a life. All suicidal persons are ambivalent about life and therefore are never $100 \%$ suicidal and approximately $80 \%$ of all potential suicidal victims give some clue before exhibiting self -destructive behavior ( Shives,.2012).

Prevention requires knowledge of the dynamics of suicide and the ability to recognize the potential for suicidal actions in every client. So, reducing mortality and morbidity from suicidal behavior remains a clinical challenge in the care of patients with schizophrenia(Pompili,Ruberto\&Tatarelli,2 004).

\section{Significance of the study}

In Egypt, there is no estimation for the incidence and prevalence of suicide among schizophrenic patients. Various studies have identified risk factors for suicide in schizophrenic patients which are of great value for prediction and prevention of selfinflicted death. Despite great efforts, both on 
the side of drug treatment and psychosocial strategies.

Nurses should be aware of their duty and responsibility towards their clients, even from themselves whenever possible. Hopefully, through all their efforts, the tide of senseless loss of life can be turned, and choices will be made looking toward life instead of away from it. Through;- decrease the risk of suicidal behavior, support effective coping strategies and promote wellbeing ( Schultz\&Videbeck,2013).

This study focus on a number of issues that are of paramount importance for the understanding and prevention of suicide in these patients through assessing nurses' awareness about relationship between suicidal ideation and positive and negative symptoms of schizophrenic patient . This study should help in future plan for, pointing the need to improve quality of care of schizophrenic patient, pointing to the need of supporting educational programs addressed to nurses and to establish a constructive nurse-patient relationship.

\section{Aim of the study}

Assess nurse's awareness of the relationship between suicidal ideation and schizophrenic patients' positive and negative symptoms.

\section{Research Question:}

1. What are nurses' level of awareness of positive and negative symptoms of schizophrenic patients?

2. Do nurses realize the relationship between positive/ negative symptoms and suicidal ideation among schizophrenic patients?

3. What are nurses' level of awareness of different clues that may indicate schizophrenic patient's early intention for suicide?

\section{Subjects And Methods}

\section{Research design}

The design for this study was a descriptive study design.

\section{Setting:}

The study was carried out in Port-Said Psychiatric and Mental Health Hospital(PSPMHH) .The hospital consists of five different departments (three males and two females departments) with bed capacity around 130 patients. Only 118 beds from them are usually occupied. From 118 patients there are nearly 74 patients who have the diagnosis of schizophrenia with its different types.

\section{Subjects:}

The subject of this study included a convenience sample nurses (male and females) . Originally total number of nurses working in (PSPMHH) were eighty seven (87) nurses . Ten percent of this number was selected to pilot study. After completion of pilot study, the total number of nurses became seventy nine (79). At the beginning of the study the number of nurses in (PSPMHH) became seventy one (71) as eight of them went on long vacation. Seventy nurses accepted to participate in the study while one nurses refused to participate therefore the total number of the subject who continued in the study became seventy nurses.

\section{Tools of data collection:}

Structured

interviewing questionnaire developed by the researcher. These questions collected and adapted from Schultz \& Videbeck (2013),Elder et al., (2013);Townsend,(2014), which includes: 


\section{First tool:}

Socio demographic data (e.g. age, gender, level of education, marital status....etc.)

\section{Second tool:}

\section{Nurses' knowledge about} schizophrenic disorders :It consists of three parts as follows:

* Part I: Nurses' educational background about schizophrenia . It include 3 questions

* Part II: Nurses' awareness of positive and negative schizophrenic symptoms. It include 8 questions, there are subside questions therefore total numbers of scores were 17 score.

* Part III: Nurses' clinical experience with schizophrenic patients. It include 5 questions.

\section{Third tool:}

Nurses' awareness of suicidal ideation in schizophrenic patients::It consists of three parts as follows:

* Part I :Nurses' awareness of suicide as a threat to schizophrenic patients. It include 10 questions.

* Part II: Nurses' awareness about suicide and its relationship to schizophrenia. It include 16 questions.

* Part III: Nurses' awareness of the relationship between suicidal ideation and positive and negative schizophrenic symptoms .It include 4 questions.

\section{Scoring system:}

The structured questionnaire sheets consists of three tools. In all questions, if the answer was correct scored one point while incorrect answer scored zero. The total scores of two tools was 47scores. The percentage of overall scores was calculated. Subsequently, nurses' level of awareness has been classified as follows; unsatisfactory level of awareness for nurses who got scores less than $60 \%$, satisfactory level of awareness for nurses who got scores equal or more than $60 \%$.

* Tool(1) : It is descriptive data, consists of (8) questions.

* Tool(2) : Consists of three parts:

-Part (1): It is descriptive data ,consists of (3) questions.

-Part(2): It consists of (8) questions, there are subside questions therefore total numbers of scores were 17 score. It's satisfactory level for answers were 10 score.

-Part (3): It is descriptive data ,consists of (5) questions.

Tool(3) :Consists of three parts:

-Part (1): It consists of (10) questions and it's score were (10) scores. It's satisfactory level for answers were 6 scores.

-Part (2): It consists of (16) questions and it's score were (16) scores. It's satisfactory level for answers were 10 scores.

-Part (3): It consists of (4) questions and it's score were (4) scores. It's satisfactory level for answers were 2 scores.

* Therefore, total number of satisfactory score for tools questions were $\mathbf{2 8}$ scores. 


\section{Operational design:}

The operational design includes preparatory phase, tool's validity, pilot study and field work.

\section{Preparatory phase:}

It includes reviewing of recent literature, different studies and theoretical knowledge of various aspects related to lifestyle risk factors using books, articles, internet, periodicals and magazines to develop tools of data collection.

\section{Tools validity:}

Content validity (or logical validity) was used for modified tools by the researchers. It was ascertained by a Jury consisting of four experts in the field of psychiatric mental health nursing and medicine for the content validity ( 3 experts in nursing field, two of them were professor and one was assistant professor, and other one was professor of psychiatric medicine). Recommended modifications were done accordingly.

\section{Pilot study:}

A pilot study was carried out after the development of the tools and before starting the data collection, it was carried out on 8 nurses $(10 \%)$ who were working inPSSMHH. The subjects included in the pilot study were excluded from the study subjects.

\section{Field work:}

The data were collected over a period of one month, the actual field work was carried out from 23 June (2015) to 23 July (2015). The researcher was available 4 days/week in all shifts ( early, late, night). The purpose of the study was explained by the researcher to all nurses (70) who were included in the study. Three interviewed questionnaire, developed by researcher, were given to each nurse to fill it in the presence of the researcher for any clarification.

\section{Administrative design:}

An official permission for collection of data was obtained using proper channels of communication. Official letters were sent from the Faculty of Nursing, Suez Canal University (SCU) to the director of study setting, explaining the aim of the study and its expected outcome. Permission from director of hospital and its head nurse have been approved to conduct the study at this hospital after obtaining permissionfrom General Secretariat of Mental Health in Abbasia hospital in Cairo ( whichtaken period from 1 May to 22 June ,2015) .Each nurse was asked to give verbal consent to participate in the studyafter full explanation of the nature ofthe studyand it's expected beneficial out comes.

\section{Ethical consideration}

The agreement for participation of the nurses was taken after explanation the aim and nature of the study. The researcher informed the nurses that participation in the study was voluntary, also they were notified that they were assured that the information would be confidential and will be used for the research propose only, and they have the right to withdraw from the study at any time.

\section{Statistical analysis:}

All data were collected, tabulated and subjected to statistical analysis. Statistical analysis is performed by SPSS in general (version 17), also Microsoft office excels is used for data handling and graphical presentation. Quantitative variables are described by the Mean, Standard Deviation (SD) Chi-squared test is used for categorical variables relations. Significance level is considered at $\mathrm{P}<0.05$, while $\mathrm{P}$-values $<0.01$ is Considered highly significant. 


\section{Results}

Socio-demographic characteristics shows that :The mean age of the studied nurses' was $27.54 \pm 6.23$ years with a range of $20-30$ years. While, $87.1 \%$ of nurses were female and $65.7 \%$ of them were married. Regarding nurses' level of education 51.4 $\%$ of them have finished technical secondary school, while only $2.9 \%$ have finished bachelor degree.57.1\% of the studied nurses had attended post scholastic studies/ training in psychiatric nursing . Regarding to their scholastic studies, $77.1 \%$ of the studied nurses have studied psychiatric nursing courses . $42.9 \%$ of them have 5 to less than 10 years' experience in psychiatric field. $77.1 \%$ of studies nurses had studied schizophrenia ,Out of this number. $42.6 \%$ of studied nurses didn't get clinical training in psychiatric field . Only $16.7 \%$ of studied nurses who reported that scholastic clinical training was enough to qualify them to work in the psychiatric hospital.

Nurses awareness of positive and negative schizophrenic symptoms.

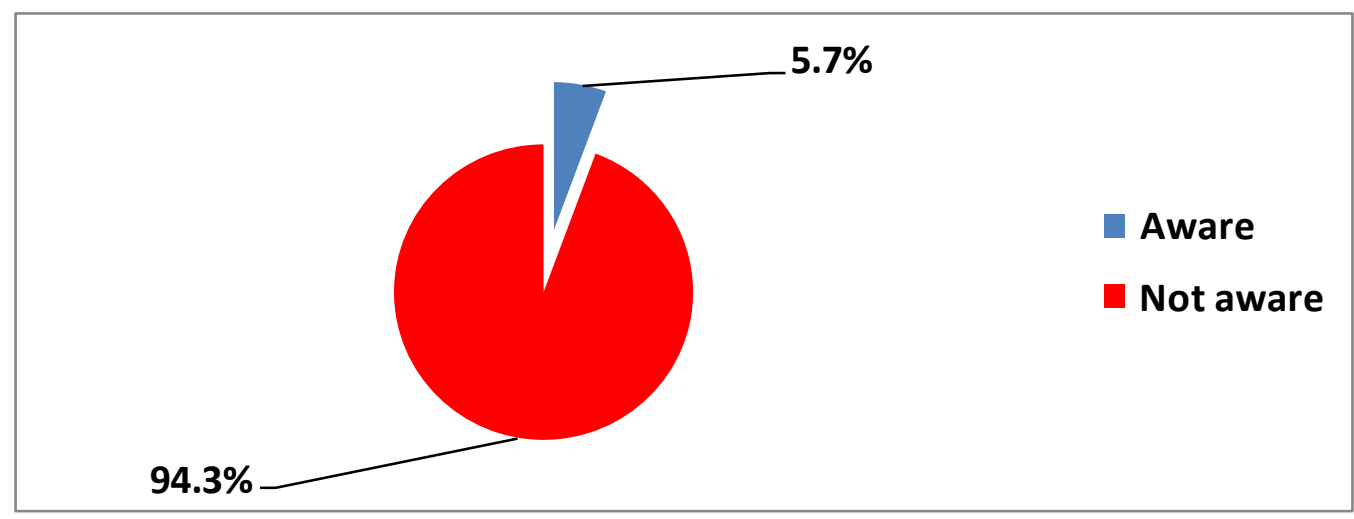

Figure (1) shows that $94.3 \%$ of studied nurses were aware of positive and negative symptoms of schizophrenia. 
Nurse's Awareness of the Relationship between Suicidal Ideation and Schizophrenic Patient's Positive/Negative Symptoms

Table (1):Difficulties in dealing with schizophrenic patients as reported by the studied nurses .

\begin{tabular}{|l|c|c|}
\hline \multicolumn{1}{|c|}{ Variables } & N & \% \\
\hline \multicolumn{1}{|c|}{ Difficulties as reported by nurses } & 34 & 48.6 \\
\hline \#Types of Difficulties:- & & \\
Lack of attention- & & 26.5 \\
Sudden Irritability - & 8 & 23.5 \\
-Suicidal attempts & 9 & 26.5 \\
-Difficulties in communication & 11 & 32.4 \\
-Suspicious in others & 6 & 17.6 \\
-Hyperactivity & 5 & 14.7 \\
- Irascible & 3 & 8.8 \\
- Harming others. & 4 & 11.8 \\
- Personal hygiene & 2 & 5.9 \\
- Labile mood & 2 & 5.9 \\
- Poor insight. & 3 & 8.8 \\
-Isolation. & 2 & 5.9 \\
- Aggressiveness & 2 & 5.9 \\
\hline
\end{tabular}

Table (1) shows that $48.6 \%$ of the studied nurses reported that they have difficulties in dealing with schizophrenic patients. $26.5 \%$ of the studied nurses reported that they have a difficulty in dealing with schizophrenic patients who attempt suicide. $32.4 \%$ of them reported that they have difficulties in communication with schizophrenic patients. Also $11.8 \%$ of the studied nurses reported that they have difficulty with schizophrenic patient when they are trying to harm others.

Table (2): Awareness of studied nurses subject about their role to prevent attempting suicide for schizophrenic patient .

\begin{tabular}{|c|c|c|c|c|}
\hline \multirow[t]{2}{*}{ Nursing intervention for suicide } & \multicolumn{2}{|c|}{ Aware } & \multicolumn{2}{|c|}{ Unaware } \\
\hline & $\mathbf{N}$ & $\%$ & $\mathbf{N}$ & $\%$ \\
\hline $\begin{array}{l}\text {-Maintain low level of stimuli in client's environment.(low lighting, few } \\
\text { people, low noise level and simple decor) }\end{array}$ & 0.0 & 0.0 & 70 & 100.0 \\
\hline - Seclusion room could be used if necessary. & 0.0 & 0.0 & 70 & 100.0 \\
\hline $\begin{array}{l}\text { - Intervene at the first sign of increased anxiety, agitation or verbal or } \\
\text { behavioral aggression. Offer empathetic response to the client's feelings. }\end{array}$ & 0.0 & 0.0 & 70 & 100.0 \\
\hline - Avoiding sitting patient alone. & 3 & 4.3 & 67 & 95.7 \\
\hline -Encourage patient to participate in physical activities. & 7 & 10.0 & 63 & 90.0 \\
\hline -Remove all dangerous objects from client's environment. & 19 & 27.1 & 51 & 72.9 \\
\hline $\begin{array}{l}\text {-Observe client's behavior frequency do this while carrying out routine } \\
\text { activities. }\end{array}$ & 15 & 21.4 & 55 & 78.6 \\
\hline -Use of mechanical restrains may be necessary & 12 & 17.1 & 58 & 82.9 \\
\hline $\begin{array}{l}\text { - Maintain calm attitude toward the client, as the client's anxiety increases } \\
\text { offer some alternative e.g talking about situation. }\end{array}$ & 25 & 35.7 & 45 & 64.3 \\
\hline - Giving emergency medication as doctor order. & 24 & 34.3 & 46 & 65.7 \\
\hline $\begin{array}{l}\text { areness of nurses About their role to prevent Attempting suicide for } \\
\text { renic patients }\end{array}$ & 0 & 0.0 & 70 & 100.0 \\
\hline
\end{tabular}


Table (2) shows that; all of the studied nurses $100 \%$ aren't aware that maintain low level of stimuli in client's environment, use of seclusion room and intervene at the first sign of increased anxiety, agitation or verbal or behavioral aggression, can be used to avoid patients' suicide. $95.7 \%$ of them aren't aware that avoiding sitting patient alone is an important actions. Also $90.0 \%$ of them aren't aware that encourage patient to participate in physical activities is an important actions that they should take to avoid patients' suicide. Finally results shows that all of studied nurses weren't aware about their role to prevent attempting suicide for schizophrenic patients.

Nurses awareness about clues made by schizophrenic patients that may indicate their early intention for suicide.

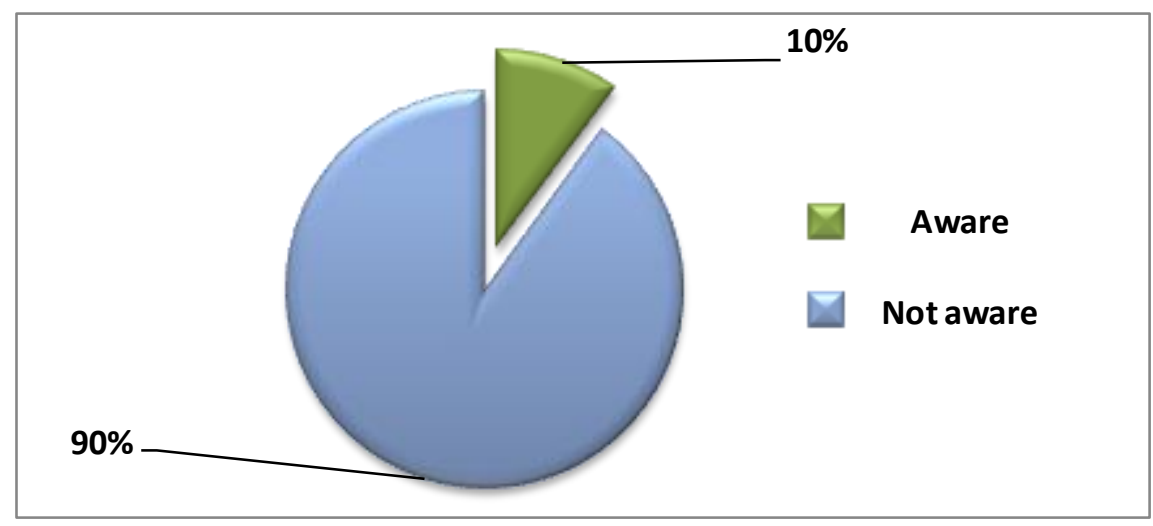

Figure (2)shows that only $10 \%$ of studied nurses subject had a satisfactory level of awareness to recognize clues made by schizophrenic patients that may indicate their early intention for suicide.

Nurses' awareness of suicide as a threat to schizophrenic patients.

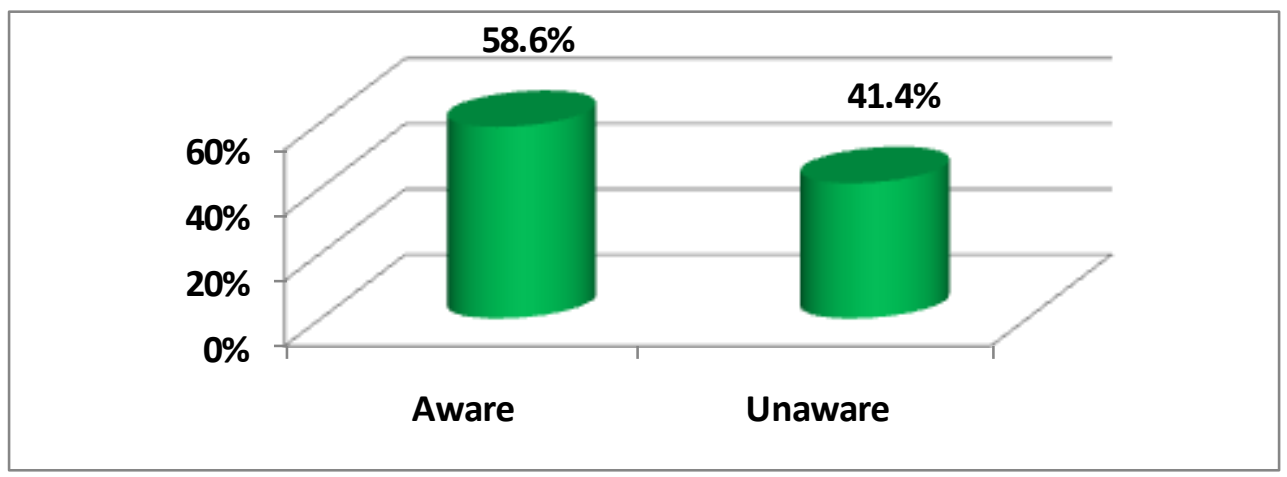

Figure (3) : shows that $58.6 \%$ of the studied nurses are aware of suicide as a threat to 
schizophrenic patients, while $41.4 \%$ of them aren't aware about that.

Nurses' awareness about suicide and its relationship to schizophrenia.

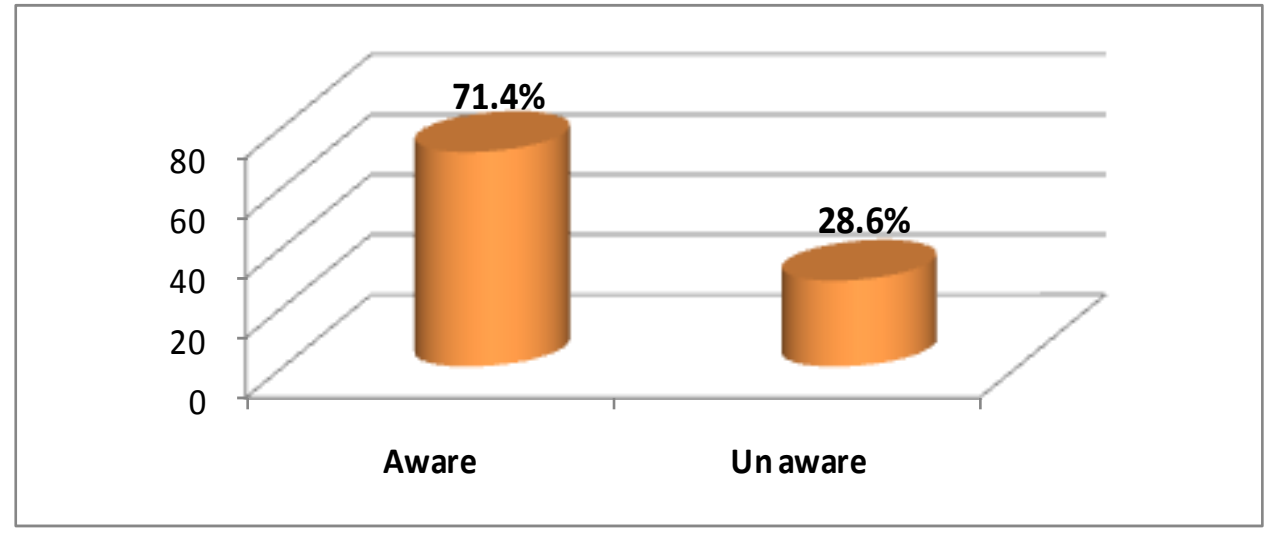

Figure (4) : shows that $71.4 \%$ of the studied nurses are aware of suicide and its relationship to schizophrenia, while $28.6 \%$ of them aren't aware about that.

Nurses' awareness of the relationship between suicidal ideation and positive and negative schizophrenic symptoms.

$45.7 \%$

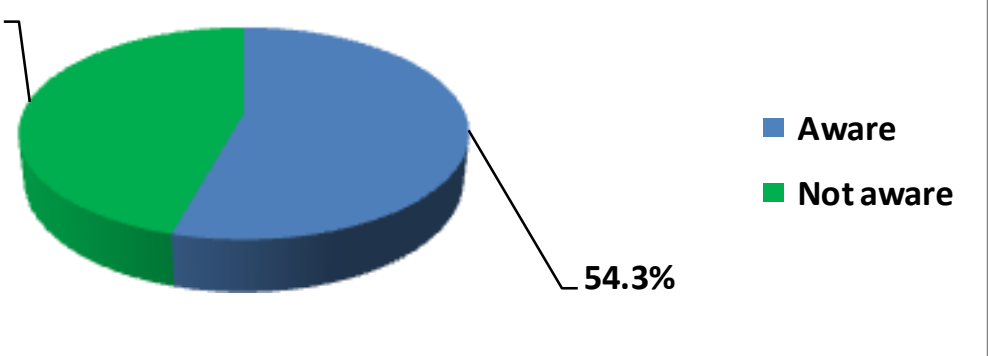

Figure (5)shows that $54.3 \%$ of the studied nurses are aware of the relationship between positive $\&$ negative symptoms of schizophrenic patients and suicidal ideation, while $45.7 \%$ of them are not aware about that.

Total awareness of relationship between suicidal ideation and positive and negative symptoms of schizophrenic patients.

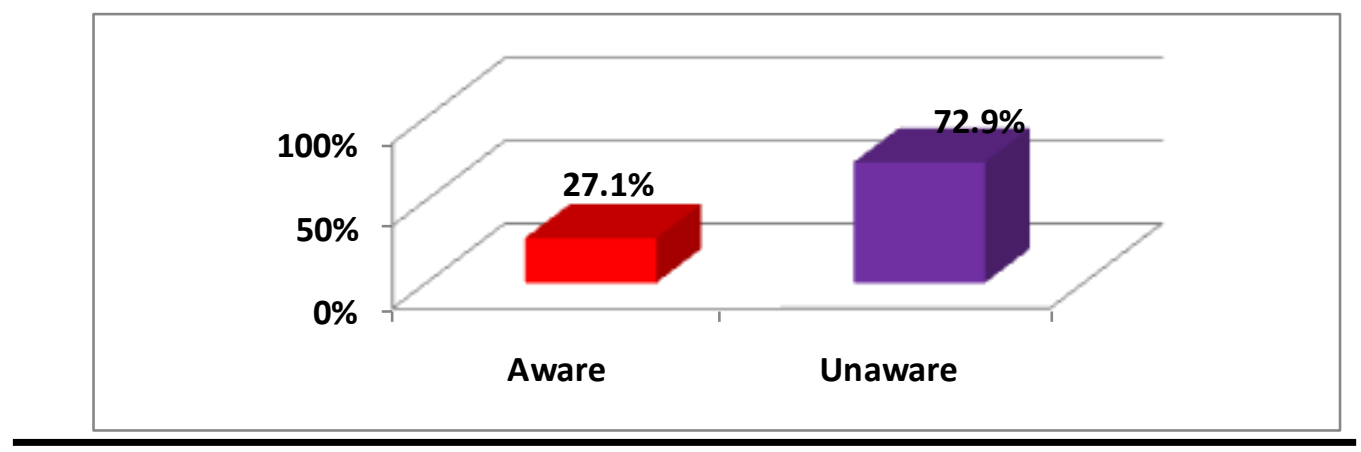


FinallyFigure (6) show that $72.9 \%$ of studied nurses were not aware about total awareness of relationship between suicidal ideation and positive and negative symptoms of schizophrenic patients.

Table (3): The relationship between socio-demographic characteristic and nurses' awareness of positive \& negative symptoms of schizophrenia

\begin{tabular}{|c|c|c|c|c|c|c|}
\hline \multirow[t]{3}{*}{ Items } & \multicolumn{4}{|c|}{$\begin{array}{c}\text { Total awareness about } \\
\text { symptoms of schizophrenia }\end{array}$} & \multirow{3}{*}{$\mathbf{X}^{2}$} & \multirow{3}{*}{ P value } \\
\hline & \multicolumn{2}{|c|}{ Not aware } & \multicolumn{2}{|c|}{ Aware } & & \\
\hline & $\mathbf{N}$ & $\%$ & $\mathbf{N}$ & $\%$ & & \\
\hline \multicolumn{7}{|l|}{-Degree of education } \\
\hline - Diploma of nursing & 31 & 47.0 & 1 & 25.0 & .978 & .613 \\
\hline - technical secondary school & 33 & 50.0 & 3 & 75.0 & & \\
\hline - bachelor & 2 & 3.0 & 0 & 0.0 & & \\
\hline \multicolumn{7}{|l|}{ - Scholastic psychiatric experience } \\
\hline • Yes & 51 & 77.3 & 3 & 75.0 & .011 & .916 \\
\hline - $\quad$ No & 15 & 22.7 & 1 & 25.0 & & \\
\hline $\begin{array}{l}\text { - Getting clinical training } \\
\begin{array}{l}\bullet \quad \text { Yes } \\
\bullet \quad \mathrm{No}\end{array}\end{array}$ & $\begin{array}{l}30 \\
22\end{array}$ & $\begin{array}{l}57.7 \\
42.3\end{array}$ & $\begin{array}{l}1 \\
1\end{array}$ & $\begin{array}{l}50.0 \\
50.0\end{array}$ & .047 & .829 \\
\hline $\begin{array}{l}\text {-Clinical training was enough to qualify to } \\
\text { work in the psychiatric hospital } \\
\text { - Yes } \\
\text { - No }\end{array}$ & $\begin{array}{c}9 \\
43\end{array}$ & $\begin{array}{l}17.3 \\
82.7\end{array}$ & $\begin{array}{l}0 \\
2\end{array}$ & $\begin{array}{c}0.0 \\
100.0\end{array}$ & .415 & .519 \\
\hline \multicolumn{7}{|l|}{-Post-scholastic studies/ training } \\
\hline - $\quad$ Yes & 24 & 66.7 & 16 & 76.2 & .001 & .977 \\
\hline - No & 12 & 33.3 & 5 & 23.8 & & \\
\hline \multicolumn{7}{|l|}{$\begin{array}{l}\text {-Numbers of years of psychiatric } \\
\text { experience }\end{array}$} \\
\hline - $\quad$ less than 5 years & 24 & 36.4 & 2 & 50.0 & 3.916 & .141 \\
\hline - $\quad$ from 5 years to 10 years & 30 & 45.5 & 0 & 0.0 & & \\
\hline - $\quad$ more than 10 years & 12 & 18.2 & 2 & 50.0 & & \\
\hline
\end{tabular}

$\mathrm{X} 2=$ Person Chi-Square Tests, Sig. at $95 \%$ Confidence Interval and $\mathrm{p}$ value $<0.05$, *= statistically significant.

Table (3) shows that there is no statistically significance relationship between sociodemographic characteristic and nurse's awareness of positive \&negative symptoms of schizophrenia 
Table (4): The relationship between socio-demographic characteristic \& total nurse's awareness of the relationship between suicidal ideation and positive and negative symptoms of schizophrenia

\begin{tabular}{|c|c|c|c|c|c|c|}
\hline \multirow[t]{3}{*}{ Items } & \multicolumn{4}{|c|}{ Total awareness } & \multirow{3}{*}{$\mathbf{X}^{2}$} & \multirow{3}{*}{$P$ value } \\
\hline & \multicolumn{2}{|c|}{ Not aware } & \multicolumn{2}{|c|}{ Aware } & & \\
\hline & $\mathbf{N}$ & $\%$ & $\mathbf{N}$ & $\%$ & & \\
\hline \multicolumn{7}{|l|}{-Degree of education } \\
\hline - $\quad$ Diploma of nursing & 25 & 49.0 & 7 & 36.8 & 1.189 & .552 \\
\hline - technical secondary school & 25 & 49.0 & 11 & 57.9 & & \\
\hline - $\quad$ bachelor & 1 & 2.0 & 1 & 5.3 & & \\
\hline \multicolumn{7}{|l|}{ - Scholastic psychiatric experience } \\
\hline • Yes & 36 & 70.6 & 18 & 94.7 & 4.578 & $.032 *$ \\
\hline - $\quad$ No & 15 & 29.4 & 1 & 5.3 & & \\
\hline $\begin{array}{c}\text { - Getting clinical training } \\
\qquad \quad \text { Yes } \\
\bullet \quad \text { No }\end{array}$ & $\begin{array}{l}23 \\
19\end{array}$ & $\begin{array}{l}54.8 \\
45.2\end{array}$ & $\begin{array}{l}8 \\
4\end{array}$ & $\begin{array}{l}66.7 \\
33.3\end{array}$ & .541 & .462 \\
\hline $\begin{array}{l}\text {-Clinical training was enough to qualify to } \\
\text { work in the psychiatric hospital } \\
\text { - Yes } \\
\text { - No }\end{array}$ & $\begin{array}{c}8 \\
34\end{array}$ & $\begin{array}{l}19.0 \\
81.0\end{array}$ & $\begin{array}{c}1 \\
11\end{array}$ & $\begin{array}{c}8.3 \\
91.7\end{array}$ & .771 & .380 \\
\hline \multicolumn{7}{|l|}{-Post-scholastic studies/ training } \\
\hline - $\quad$ Yes & 20 & 66.7 & 20 & 74.0 & .005 & .945 \\
\hline - $\quad$ No & 10 & 33.3 & 7 & 26.0 & & \\
\hline \multicolumn{7}{|l|}{$\begin{array}{l}\text { Numbers of years of psychiatric } \\
\text { experience }\end{array}$} \\
\hline - less than 5 years & 17 & 33.3 & 9 & 47.4 & 1.908 & .385 \\
\hline - $\quad$ from 5 years to 10 years & 22 & 43.1 & 8 & 42.1 & & \\
\hline - $\quad$ more than 10 years & 12 & 23.5 & 2 & 10.5 & & \\
\hline
\end{tabular}

$\mathrm{X} 2=$ Person Chi-Square Tests, Sig. at 95\% Confidence Interval and $\mathrm{p}$ value $<0.05, *=$ statistically significant.

Table (4) shows that there is statistically significance relationship between scholastic psychiatric experience\&total nurse's awareness of the relationship between suicidal ideation and positive and negative symptoms of schizophrenia $(\mathrm{X} 2=4.578, \mathrm{P}$ value $=032 *)$.

\section{Discussion}

Positive symptoms such as disordered thoughts, delusions and hallucinations, it responds well to medication (Kneisl \& Trigoboff, 2009). Negative symptoms are deficits of normal emotional responses or of other thought processes, and responds less well to medication. There is relationship between positive and negative symptoms of schizophrenic patient and attempting suicide (Smith, Weston \& Lieberman,2010).

The nurse staff has an important role in reducing the incidence of suicide in schizophrenic patients. They need for continuous training for applying this training to improve the standard of patient care. It has been observed that there are schizophrenic inpatients who attempted suicide in PSPMHH. This caused by lack of awareness of the nursing staff of their role with 
schizophrenic patient. Therefore, the greater awareness of nursing staff about relationship between positive and negative symptoms of schizophrenic patient and suicidal ideation ,the greater awareness about their role thus will lead to low incidence of schizophrenic inpatients who attempt suicide.

Interpretation and discussion of results obtained from the current study were presented in four main sections; the first section describes socio-demographic characteristics of the studied nurses subjects, the second section concerns the nurses' level of awareness of positive and negative symptoms of their schizophrenic patients, the third section describes nurses' level of awareness about different clues that may indicate schizophrenic patient's early intention for suicide, Finally forth section concerns with the relationship between positive and negative symptoms of schizophrenic patients and suicidal ideation.

\section{Section I: Socio-demographic characteristics of studied nurses subject and its relations with their awareness:}

In relation to nurses' characteristics, the finding of the present study revealed that , nearly three quadrant of the studied nurses sample were between 20-29 years of age this results in accordance with the finding of Mohammed, (2007) who carried out a study in Elmnofiya university hospital entitled "Relationship between positive and negative of schizophrenia and suicidal ideation and nurses awareness about their role" and reported that highest percentage of nurses belonged to 20 to less than 40 years age group. From researcher point of view and according research results, although the majority of nurses in this study in the productive stage of knowledge, but nearly three quadrant of them aren't aware of the relationship between suicidal ideation and positive and negative symptoms of schizophrenia, possibly because many factors may be due to $22.9 \%$ of them don't studying psychiatric course during scholastic studies. Also there were $42.6 \%$ of nurses who were, studying psychiatric courses during scholastic studies, don't getting clinical training in psychiatric courses. This is very apparent through dissatisfaction of majority of nurses about quality of psychiatric course which they have studied.

As regards to the level of education, the present result revealed that above half of nurses had finished technical secondary school and according to the research results, the educational qualification had no effect on the nurses' awareness. This result disagreed with( Engin\&Cam,2009) who conducted study entitled "Effect of self-awareness Education on the self-efficacy and sociotropy-autonomy characteristics of nurses in a psychiatry clinic" and reported that the educational qualification had a positive effect on the nurses' awareness, thoughts, and behaviors in the psychiatry clinic. From researcher point of view, this disagreement may be related to numbers of factors which influence level of education such as numbers of years of working, disinterested nurses in psychiatric field and they aren't updating their knowledge.

According to experience in psychiatric field, the current study shows that less than half of nurses had experience from 5 to less than 10 years. According to research results, there is no significant relationship between number of years of experience and level of awareness. In contrast from this results (Kumar, Mehta \& Kalra, 2011) who conducted study entitled " Knowledge of staff nurses regarding legal and ethical responsibilities in the field of psychiatric nursing " and reported that there is significant relationship between numbers of years of experience and knowledge of the study subjects regarding various major psychiatric disorders .

In our point of view, this disagreement may be due to several factors 
such as inability of nurses to differentiate between positive and negative symptoms of schizophrenia, The limited number of nursing compared with large hospital capacity which does not enable them for good observation to patients with schizophrenia in terms of positive and negative symptoms(4-5 nurses in every department: nearly 40 patients), low level of knowledge of nurses and lack of courses which consequence affect their level of awareness.

As regards to scholastic schizophrenic experience, the present study showed that more than three quadrant of nurses had studied schizophrenia. According to research results, there is significant relationship between scholastic psychiatric studies and their level of awareness. In researcher point of view, this because scholastic schizophrenic studies had a positive effect on nurses' awareness of positive and negative symptoms and its relationship with suicidal ideation.

Regarding to getting scholastic clinical training in psychiatric field, the present study shows that more than half of nurses, who had studying psychiatric courses, had getting clinical training. According to research result, there is no significant relationship was found between getting clinical training and level of awareness. In contrary to the results (Mariam, Bedaso, Ayano \& Ebrahim,2016) who conducted study entitled "Knowledge, attitude and factors associated with mental illness among nurses working in public hospitals" and reported that those nurses who have took clinical training are two times more likely to be knowledgeable than those who do not took clinical training. In our point of view, disagreement may be due to; ineffective clinical training in Egypt during scholastic studies, short period of training, disinteresting nurses in psychiatric field who are forced to enter nursing field for employment, moreover; it cannot be ignored the high percentage of nurses who did not get scholastic clinical training and that surly had an effect on nurses' level of awareness.

Section II: Nurses' level of awareness of positive and negative symptoms of their schizophrenic patients:

Regarding nurses' level of awareness of positive and negative symptoms of schizophrenic patients, the current study shows that majority of nurses weren't aware of positive and negative symptoms of schizophrenia. Meanwhile this finding disagreed with (Kumar, Mehta \& Kalra, 2011) who reported that majority of nurses had a moderate knowledge in psychiatric field. In our point of view, this disagreement may be due to inadequate or insufficient scholastic psychiatric courses, inadequate scholastic clinical training, disinteresting nurses to update their knowledge and limited numbers of nurses compared to large numbers of patients (4-5 nurses in every department: nearly 40 patients).

In relation to difficulties that facing nurses in dealing with schizophrenic patient, current study show that less than half of nurses reported that they face difficulties. Slightly above one quadrant of them reported that they find difficulties in dealing schizophrenic patients with suicidal attempts. Thus, in turn, had an effect on their role with schizophrenic patients to prevent occurrence of suicide. So, continuous courses must be given to psychiatric nurses to increase their awareness of the relationship between suicidal ideation and positive and negative symptoms of schizophrenia.

\section{Section III: Nurses' level of awareness of different clues that may indicate schizophrenic patient's early intention for suicide}

Concerning to awareness of nurses about clues that may indicate early intention of suicide, the current study show that only ten percentage of nurses were aware about clues that may indicate early intention of 
suicide, Our finding is inconsistent with (Tofthagen,Talseth\&Fagerstrom,2014) who conducted study entitled " Mental health nurses' experiences of caring for patients suffering from self-harm" and found that mental health nurses were able to observe signs of self-harm and sometimes experienced a sense of intuition regarding a patient's impending self-harm. Our findings are also disagreed with (Sun, Long, Boore $\boldsymbol{\&}$ Tsao, 2006) who conducted study entitled "A theory for the nursing care of patients at risk of suicide" and found that nurses observed overt and covert suicidal clues (verbal and behavioral) displayed by psychiatric patients. This disagreement may be due to low level of nurses' knowledge and lack of presence of continuous courses specified in early warning signs of suicide as general in psychiatric field and particularly in schizophrenia.

Concerning to answers about clues that may indicate early intention of suicide current study shows that less than one quadrant of nurses were aware that verbal expression of death threats as early clues that may indicate early intention of suicide ,also less than one quadrant from the studied nurses who were aware that when patient is searching about sharp object, this is considered as a clues for suicide. This are important factors which should be known to staff nurses, lack of knowledge about them will lead to more suicidal patients.

Regarding to nurses' awareness about their role to prevent attempting suicide in schizophrenic patient, current study showed that all of nurses weren't have satisfactory level of awareness about their role, where all of nurses were not aware that maintain low level of stimuli in client's environment as nursing intervention should be taken to prevent attempting suicide. Also more than three quadrant of them were not aware that close observation to client behavior is very important step that should be taken to prevent occurrence of suicide. On the same line (Betz, Miller, Barber \& collegues., 2013) who conducted study entitled "Lethal means restriction for suicide prevention: Beliefs and behaviors of emergency department providers and found that there were "large gaps in provider training, bias in treating patients with mental health issues, and skepticism about the effectiveness of suicide prevention approaches". Also (Puntil, York, Limandri \& collegues., 2013) who conducted study entitled "Competency-based training for PMH nurse generalists: Inpatient intervention and prevention of suicide" and reported that there is a gap in suicide-specific intervention training in educational programs.

In contrast from this results Mohammed (2007) who carried out a study and reported that majority of nurses were aware about their role to prevent occurrence of suicide. In our point of view this disagreement may be due to less than half of studied nurses sample where diplome and they don't taken satisfactory content of information about suicide and how they can prevent it .As well as we can't deny that less than half of nurses don't get scholastic clinical training in psychiatric course which had an direct effect on their awareness about their role.

Section IV: Nurses' level of awareness of relationship between suicidal ideation and positive and negative symptoms of schizophrenic patients

Concerning nurses' knowledge about suicide as a threats to schizophrenic patients, the current study shows that more than half $(58.6 \%)$ of them were aware of that. This results was disagreed with (Kawanishi, Sato, Yamada \& collegues., 2006) who conduct a study in Japan entitled "Knowledge and attitudes of psychiatric nurses and nursing students concerning current suicide-related issues " and reported that nursing students and even nurses at a mental hospital and psychiatric social workers 
showed serious knowledge gaps concerning suicide and they are causes of current problem of increasing suicide. In our point of view, this disagreement may be due to presence of suicidal attempt in (PSPMHH) which lead to increase awareness of them about suicide. In my observation as an instructor with students at PSPMHH, there were increased in number of suicidal victims at hospital due to lack of nurses awareness about suicide clues which directly affect nurses' role to prevent occurrence of suicide such as close observation to patients. Therefore, there is a keen interest from the responsible persons at hospital to nursing staff to increase awareness about suicide and their role to curb it.

As regarding nurses knowledge about schizophrenia and it's relation to suicide, the current study shows that nearly three quadrant of nurses were aware about schizophrenia and its relation to suicide. This results was disagreed with (Deribew\&Tesfaye,2005) who conducted study entitled " Assessment of knowledge, attitude and practice of nursing staff towards mental health problems in Jimma Zone, South Western Ethiopia" and reported that three quadrant of the nurses labeled schizophrenia as minor disease with poor knowledge about its prevalence, definition and relations with suicide. This disagreement may be due to increase numbers of schizophrenic patients in (PSSMHH), where nearly two-thirds of psychiatric patients in this hospital are schizophrenic patients, with increase numbers of years of experience where more than one third of studied nurses sample had from 5 to less than 10 years' experience in psychiatric hospital.

\section{Conclusion}

Most studied nurses sample weren't aware of positive and negative symptoms of schizophrenia. Majority of studied nurses sample weren't aware of the relationship between suicidal ideation \& positive and negative symptoms of schizophrenia. While all of them didn't have the ability to recognize clues made by schizophrenic patients that may indicate early intention of suicide.

\section{Recommedation}

- Orientation programs/seminars about the existence of the relationship between specific positive \&negative symptoms of schizophrenia and suicidal ideation.

- Training programs should be constructed to update the skills and knowledge of nurses dealing with psychiatric patients who are attempt suicide, in meaning of early warning signs of suicide( clues of suicide) and nursing intervention to prevent occurrence of suicide.

- National survey to measure suicidal ideation among schizophrenic patients in Egypt.

\section{References}

Betz, M. E., Miller, M., Barber, C., Miller, I., Sullivan, A. F., Camargo Jr., C. A., \& Boudreaux, E. D. (2013).Lethal means restriction for suicide prevention: Beliefs and behaviors of emergency department providers. Depression and anxiety. 30(10), 1013-1020.

Crisp, R.\& Turner, R. (2014). Essential social psychology. 3rd ed. London, Sage. p 568.

Deribew, A. \&Tesfaye,M.(2005). Assessment of knowledge, attitude and practice of nursing staff towards mental health problems in Jimma Zone, South Western Ethiopia.Age, 18(24), 25-31..

Engin, E., \& Cam, O. (2009).Effect of selfawareness Education on the self-efficacy and sociotropy-autonomy characteristics of nurses in a psychiatry clinic. Archives of psychiatric nursing, 23(2), 148-156.

Gavaudan, G., Besnier, N., \&Lançon, C. (2006).Suicide et schizophrénie: évaluation du risque et prévention. In AnnalesMédicopsychologiques, revue psychiatrique .Elsevier Masson. 164(2), 165-175.

Isik, E.(2007). SizofreniveDepresyon. GuncelSizofreni. G.M. MatbaacilikveTicaret, Ankara, 266-272(Turkish).

Kawanishi ,C. ,Sato, R. Yamada,T., Suda,A., Hirayasu,Y.\& Ikeda .H.(2006). Knowledge and attitudes of nurses, nursing students and psychiatric social workers concerning current suicide-related issues in Japan, Radcliffe 
Publishing, Primary Care Mental Health;4,(4),285-292.

Kelly, D. L., Shim, J. C., Feldman, S. M., Yu, Y., \& Conley, R. R. (2004). Lifetime psychiatric symptoms in persons with schizophrenia who died by suicide compared to other means of death. Journal of Psychiatric Research, 38(5), 531-536 Available from http://www.ncbi.nlm.nih.gov/pubmed/153804 04 accessed 2/3/2015

Kneisl, C.\&Trigoboff, E.(2009).Contemporary Psychiatric-Mental Health Nursing. $2^{\text {nd }}$ ed. London, Pearson Prentice Ltd. p. 371.

Koslow, S. H., Ruiz, P., \&Nemeroff, C. B. (2014). A concise guide to understanding suicide: epidemiology, pathophysiology and prevention. $1^{\text {st }}$ ed. U.K. Cambridge University Press . p.406.

Kumar R., Mehta, S.\&Kalra, R.(2011). Knowledge of staff nurses regarding legal and ethical responsibilities in the field of psychiatric nursing. Nursing Midwifery Research Journal. 7(1),11.

Mariam, M. G., Bedaso, A., Ayano, G., \&Ebrahim, J. (2016). Knowledge, attitude and factors associated with mental illness among nurses working in public hospitals, Addis Ababa, Ethiopia. Journal Mental Disorder Treatment. 2(108), 2.

Mohammed, M .M.(2007). Relationship between positive and negative of schizophrenia and suicidal ideation and nurses awareness about their role.

Pompili, M., Ruberto, A. \&Tatarelli, R., 2004. Suicide in anorexia nervosa: A metaanalysis. International Journal of Eating Disorders, 36(1), pp.99-103.

Puntil, C., York, J., Limandri, B., Greene, P., Arauz, E., \& Hobbs, D. (2013).Competencybased training for $\mathrm{PMH}$ nurse generalists: Inpatient intervention and prevention of suicide. Journal of theAmerican Psychiatric Nurses Association, 19(4), 205-210.
Schultz, J. M.\&Videbeck. S.L.(2013). Lippincott's manual of psychiatric nursing care plans. $9^{\text {th }}$ ed. Philadelphia. Lippincott Williams \& Wilkins. p.173-195.

Shives, L. (2012). Basic Concepts of Psychiatricmental Health Nursing. 8th ed. China. Lippincott Williams \& Wilkins/Wolters Kluwer Health. p 623.

Smith ,T., Weston, C.\& Lieberman. J.(2010). Schizophrenia (maintenance treatment). Am Fam Physician. 82(4),338-339.

Sun, F.K., Long, A., Boore, J., \&Tsao, L.I .(2006). A theory for the nursing care of patients at risk of suicide. Jon Wiley\& Sons. Journal of Advanced Nursing .53(6), 680-690.

Taylor, M. \&Hor , K. (2010). Suicide and schizophrenia: a systematic review of rates and risk factors. Journal of psychopharmacology, 24, 81-90. Available from

http://www.ncbi.nlm.nih.gov/pmc/articles/PM C2951591/ accessed 21/2/2016.

Tofthagen, R., Talseth, A.G.\&Fagerström, L.(2014). Mental health nurses' experiences of caring for patients suffering from self-harm. Nursing Research and Practice.Available fromhttp://dx.doi.org/10.1155/2014/905741 accessed 20/8/2016.

Townsend, M . C. (2014). Essentials of psychiatric/mental health nursing : concepts of care in evidence-based practice . 6th ed., Philadelphia, PA: FA. Davis p: 318-397.

Yildiz, M., Yazici, A.\&Boke, O.(2010) : Demographic and clinical characteristics in schizophrenia: a multicenter cross-sectional case record study. Turk PsikiyatriDerg; 21(3),213-224

Yung, A. R., \&McGorry, P. D. (2012). The prodromal phase of first-episode psychosis: past and current conceptualizations. Schizophrenia bulletin, 22(2), 353-370. 